\begin{tabular}{|c|c|c|c|c|c|}
\hline \multirow{2}{*}{$\mathcal{U}$} & W R E & 12343 & \multirow{2}{*}{ WILEY } & Dispatch: 14.11.18 & CE: Saravanan S \\
\cline { 2 - 3 } & Journal Code & Manuscript No. & & No. of pages: 13 & PE: Kaviarasi N. \\
\hline
\end{tabular}

DOI: $10.1111 /$ wre. 12343

\title{
Variability in seedling emergence for European and North American populations of Abutilon theophrasti
}

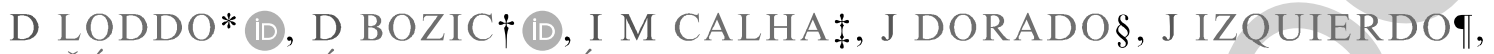 \\ M ŠĆEPANOVIĆ**, K BARIĆ**, S CARLESI†† D, R LESKOVSEK $+\ddagger$,

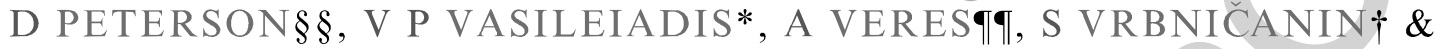

$211 \mathrm{R} \mathrm{MASIN} * * *$ (D)

*Institute of Agro-environmental and Forest Biology, National Research Council of Italy, Legnaro, Italy, $\dagger$ Faculty of Agriculture, University of Belgrade, Zemun-Belgrade, Serbia, $¥$ Instituto Nacional de Investigação Agrária e Veterinária, IP, Oeiras, Portugal, §Institute of Agricultural Sciences, CSIC, Madrid, Spain, $\mid$ Department of Agri-food Engineering and Biotechnology, Universitat Politècnica de Catalunya, Castelldefels, Spain, ${ }^{* *}$ Faculty of Agriculture, University of Zagreb, Zagreb, Croatia, ††Institute of Life Sciences, Scuola Superiore Sant’Anna, Pisa, Italy, $\$$ \$Agricultural Institute of Slovenia, Ljubljana, Slovenia, $\S \S N o r t h$ Central Soil Conservation Research Laboratory, Agricultural Research Service, US Department of Agriculture, Morris, MN, USA, qףPlant Protection Institute, SZIE, Gödöllö, Hungary, and ***Department of Agronomy, Food, Natural Resources, Animals and Environment, DAFNAE, University of Padua, Legnaro, Italy

Received 27 February 2018

Revised version accepted 24 October 2018

3 Subject Editor: Rob Freckleton, Sheffield, UK

\section{Summary}

Abutilon theophrasti is a weed that is spreading worldwide and that has had to adapt to different combinations of environmental conditions. Wide interpopulation variability has been reported regarding dormancy and germination. This variability, controlled by the interaction of genetic diversity and maternal effect, could hinder the adoption of Integrated Weed Management

5 (IWM) tools. A collaborative project was conducted to compare emergence dynamics of 12 European and North American populations under diverse environmental conditions. The main aim was to assess interpopulation variability and explain this according to environmental conditions in the seed collection sites. Seeds were sown at six experimental sites, and seedling emergence was monitored. The AlertInf model was tested to evaluate its ability to predict emergence dynamics of the different populations. A wide interpopulation variability was observed for emergence percentage and dynamics with consistent trends across sites and related to different seed dormancy levels. Populations from Catalonia, Iowa and Minnesota reached higher emergence percentage with earlier and concentrated emergence flushes probably due to low dormancy level, while populations from Croatia, Serbia and Hungary, given their low average emergence percentage, presented high dormancy levels. Good predictive accuracy of AlertInf model was obtained at the different sites, confirming the possibility of adopting it across a wide range of environmental conditions. Achieving a better knowledge of interpopulation variability can allow specific control strategies to be designed, facilitating the replacement of solely herbicide-based management with true IWM.

Keywords: velvetleaf, population variability, germination, emergence, emergence modelling.

Loddo D, Bozic D, Calha im, Dorado J, Izquierdo J, Šćépanović M, Barić K, Carlesi S, Leskovsek R, Peterson D, Vasileiadis VP, Veres A, Vrbaičanin S, Masin R (2018). Variability in seedling emergence for European and North American populations of Abutilon theophrasti. Weed Research. https://doi.org/10.1111/wre.12343.

Correspondence: D Loddo, Institute of Agro-environmental and Forest Biology, National Research Council of Italy, 35020 Legnaro, Italy. Tel: 


\section{Introduction}

Weeds can be considered pioneer species that colonise frequently disturbed habitats, such as cultivated fields, so they have to adapt their biological cycles to the specific environmental disturbances caused by farming operations. Since germination is a crucial moment in the life cycle of annual weeds, and germination timing strongly affects their survival probability, competitive ability and reproductive success (Berti et al., 2008), local populations of globally widespread species have therefore adapted to germinate at the most favourable time to emerge according to different combinations of environmental and agronomic conditions. Consequently, weeds may present wide intra-specific variability regarding dormancy and germination ecology (Eslami, 2011; Loddo et al., 2014). For example, populations growing in cold areas have been reported to have lower base temperature for germination and less dormant seeds (Loddo et al., 2013; Tozzi et al., 2014) than those in temperate areas. The variability is affected by the interaction of genetic diversity and maternal effect, that is the environmental conditions experienced during growth of mother plants and seed ripening (Andersson \& Milberg, 1998; Karlsson et al., 2008; Gesch et al., 2016). This variability could hinder the broad adoption of Integrated Weed Management (IWM) strategies and tools, which were often developed for local weed populations growing under specific conditions.

Abutilon theophrasti Medik. is an important weed spreading worldwide in spring-summer crops with a relevant economic impact in many European countries (Recasens et al., 2005). Several studies have been conducted on different aspects of $A$. theophrasti biology and ecology, such as germination (Dorado et al.,

2009a; Masin et al., 2010a,b), seedling emergence (Dorado et al., 2009b; Masin et al., 2012, 2014), seedbank dynamics (Liebman et al., 2014) and competition (Vrbnicanin et al., 2017). Contrasting information has been reported about the intra-specific variability of $A$. theophrasti germination and seedling emergence. Nurse and DiTommaso (2005) described variability of seed size, seed coat and dormancy due to different crop competition levels, and Dorado et al. (2009b) observed differences in field emergence patterns of populations in Portugal and Spain. In contrast, similar values of base temperature for germination were reported for European and Iranian populations (Loddo et al., 2013, 2018). No exhaustive studies are available comparing germination and seedling emergence among several populations of A. theophrasti, and most of the existing information can only be considered representative of local situations.
A collaborative project was therefore conducted to compare the emergence dynamics of several European and North American populations across different sites under diverse environmental conditions. The main aim was to assess the intra-specific variability and to identify patterns explaining this variability according to environmental conditions in the seed collection sites. In addition, an existing emergence predictive model AlertInf, created in Veneto, north-eastern Italy (Masin et al., 2010a,b), was tested to evaluate its ability to predict the emergence dynamics of the different populations of A. theophrasti across different sites. This information is intended to facilitate the development and adoption of tailored IWM strategies according to specific characteristics of local populations.

\section{Materials and methods}

\section{Seed source}

Seeds were collected during summer-autumn 2013 from spontaneous populations of $A$. theophrasti at 12 different sites in Europe and United States: two in Spain (pop. MAD-Madrid and CAT-Catalonia), Italy (pop. TUS-Tuscany and VEN-Veneto) and United States (pop. IOWA-Iowa and MIN-Minnesota) and one each in Croatia, Greece, Hungary, Portugal, Serbia and Slovenia (pop. CRO, GRE, HUN, POR, SER and SLO). Geographical and climatic information on the collection sites is presented in Table 1. The sites are characterised by different climates, ranging from the warmer conditions in Pisa (Italy), Golegã (Portugal) and Arganda del Rey (Spain) to the colder conditions in Monona and Morris (Iowa and Minnesota, USA). Seeds were collected from several plants to obtain a representative sample of the whole population. Seeds were cleaned and left to dry at room temperature $\left(20^{\circ} \mathrm{C}\right)$ for some days and then stored in paper bags at room temperature for 4 weeks until the start of the experiment. Storage duration and conditions were the same for all 12 populations.

\section{Preliminary tests}

Seed dry weight (expressed as 1000 seeds weight) was measured by weighing four 1000 seed replicates per population after drying at $65^{\circ} \mathrm{C}$ for $48 \mathrm{~h}$. Means and SE were calculated, and the Tukey HSD test $(P<0.05)$ was used to detect significant differences between means. Seed germinability of the different populations was assessed in a preliminary experiment. Physical dormancy was removed by soaking seeds in boiling water for $10 \mathrm{~s}$ (Nurse \& DiTommaso, 2005) 
Table 1 List of Abutilon theophrasti populations with geographical and climate information of their collection sites

\begin{tabular}{|c|c|c|c|c|c|c|}
\hline $\begin{array}{l}\text { Population } \\
\text { code }\end{array}$ & Country & Site & Latitude & Longitude & Altitude & Climate* $^{*}$ \\
\hline MIN & USA & Morris & $45^{\circ} 35^{\prime} \mathrm{N}$ & $95^{\circ} 54^{\prime} \mathrm{W}$ & 350 & Dfb (Snow, fully humid with warm summer) \\
\hline IOWA & USA & Monona & $43^{\circ} 03^{\prime} \mathrm{N}$ & $91^{\circ} 23^{\prime} \mathrm{W}$ & 360 & Dfa (Snow, fully humid with hot summer) \\
\hline POR & Portugal & Golegã & $39^{\circ} 24^{\prime} \mathrm{N}$ & $8^{\circ} 29^{\prime} \mathrm{W}$ & 20 & $\begin{array}{l}\text { Csa (Warm temperate with dry and hot } \\
\text { summer) }\end{array}$ \\
\hline MAD & Spain & $\begin{array}{l}\text { Arganda del } \\
\text { Rey }\end{array}$ & $40^{\circ} 19^{\prime} \mathrm{N}$ & $3^{\circ} 29^{\prime} \mathrm{W}$ & 550 & $\begin{array}{l}\text { Csa (Warm temperate with dry and hot } \\
\text { summer) }\end{array}$ \\
\hline САT & Spain & Lleida & $41^{\circ} 37^{\prime} \mathrm{N}$ & $0^{\circ} 38^{\prime} \mathrm{E}$ & 150 & $\begin{array}{l}\text { Cfa (Warm temperate, fully humid with hot } \\
\text { summer) }\end{array}$ \\
\hline TUS & Italy & Pisa & $43^{\circ} 40^{\prime} \mathrm{N}$ & $10^{\circ} 20^{\prime} \mathrm{E}$ & 2 & $\begin{array}{l}\text { Csa (Warm temperate with dry and hot } \\
\text { summer) }\end{array}$ \\
\hline VEN & Italy & Legnaro & $45^{\circ} 20^{\prime} \mathrm{N}$ & $11^{\circ} 58^{\prime} \mathrm{E}$ & 15 & $\begin{array}{l}\text { Cfa (Warm temperate, fully humid with hot } \\
\text { summer) }\end{array}$ \\
\hline SLO & Slovenia & Murski Črnci & $46^{\circ} 38^{\prime} N$ & $16^{\circ} 06^{\prime} \mathrm{E}$ & 192 & $\begin{array}{l}\text { Cfb (Warm temperate, fully humid with warm } \\
\text { summer) }\end{array}$ \\
\hline CRO & Croatia & Čazma & $45^{\circ} 45^{\prime} \mathrm{N}$ & $16^{\circ} 37^{\prime} \mathrm{E}$ & 120 & $\begin{array}{l}\text { Cfb (Warm temperate, fully humid with warm } \\
\text { summer) }\end{array}$ \\
\hline HUN & Hungary & Rackeve & $47^{\circ} 09^{\prime} \mathrm{N}$ & $18^{\circ} 54^{\prime} \mathrm{E}$ & 100 & $\begin{array}{l}\text { Cfb (Warm temperate, fully humid with warm } \\
\text { summer) }\end{array}$ \\
\hline SER & Serbia & $\begin{array}{l}\text { Rimski } \\
\text { Sancevi }\end{array}$ & $45^{\circ} 40^{\prime} \mathrm{N}$ & $19^{\circ} 05^{\prime} \mathrm{E}$ & 00 & $\begin{array}{l}\text { Cfb (Warm temperate, fully humid with warm } \\
\text { summer) }\end{array}$ \\
\hline GRE & Greece & Makrohori & $40^{\circ} 32^{\prime} \mathrm{N}$ & $22^{\circ} 14^{\prime} \mathrm{E}$ & 60 & $\begin{array}{l}\text { Cfa (Warm temperate, fully humid with hot } \\
\text { summer) }\end{array}$ \\
\hline
\end{tabular}

*Climate classification according to the updated Köppen-Geiger classification (Kottek et al., 2006).

and then placing them in Petri dishes on filter paper moistened with $5 \mathrm{~mL}$ of deionised water. Petri dishes were then incubated at $20^{\circ} \mathrm{C}$ with 12 -h light/12-h dark photoperiod. Three replicates of 50 seeds each were included per population. After one week of incubation, germination surpassed $75 \%$ for all populations (data not shown), so problems of germinability were excluded.

\section{Field experiment for emergence monitoring}

Seeds of the 12 populations were sown in November 2013 at six different experimental sites in Southern and Eastern Europe: (i) Oeiras, Lisbon (Portugal), (ii) Arganda del Rey, Madrid (Spain), (iii) Viladecans, Catalonia (Spain), (iv) Legnaro, Veneto (Italy), (v) Zagreb (Croatia), (vi) Belgrade (Serbia). Soil characteristics and climatic classification of the six experimental sites are reported in Table 2. All sites are characterised by a warm temperate climate with differences regarding the amounts of precipitation and summer temperatures. Soil texture ranged from sandy loam at Zagreb (Croatia) to silt loam at Belgrade (Serbia) and Legnaro (Italy). Seeds were mixed with local soil and distributed randomly in the top $2 \mathrm{~cm}$ soil layer. Four replicates were included for each population. Replicates were made up of 250 seeds for CAT, CRO, HUN, VEN, POR, SER, MAD, TUS, 150 seeds for
SLO and 100 for GRE, IOWA, MIN in accordance with the availability of seeds. Each replicate occupied a single $1-\mathrm{m}^{2}$ plot, and the experimental sites were set up in areas where no spontaneous population of A. theophrasti had been observed. Weather conditions (daily air and soil temperature and rainfall) were monitored throughout the experiment. Emerged seedlings were counted and removed weekly during the typical period of $A$. theophrasti emergence (normally from February to August).

\section{Data analysis}

Mean and SE were calculated for emergence percentage of each population at each experimental site, as well as for average emergence percentage of each population (considering the data of all replicates across the different experimental sites) and each experimental site (considering the data of all replicates of the different populations). Emergence percentage was analysed using a generalised mixed model with a binomial distribution, assuming the emergence percentage as the probability of a single seed germinating and emerging or not. Variance was weighted by the number of seeds in each replicate. The random part of the model consisted of a nested design; replicates were nested within population, which were nested within the experimental site. Models were created using lme4 (Bates et al., 
Table 2 List of experimental sites with geographical, climate and soil characteristics information

\begin{tabular}{|c|c|c|c|c|c|c|c|c|c|c|c|}
\hline \multirow[b]{2}{*}{ Site } & \multirow[b]{2}{*}{ Country } & \multirow[b]{2}{*}{ Latitude } & \multirow[b]{2}{*}{ Longitude } & \multirow[b]{2}{*}{ Altitude } & \multirow[b]{2}{*}{ Climate* } & \multicolumn{6}{|c|}{ Soil characteristics } \\
\hline & & & & & & $\begin{array}{l}\text { Sand } \\
\%\end{array}$ & $\begin{array}{l}\text { Loam } \\
\%\end{array}$ & $\begin{array}{l}\text { Clay } \\
\%\end{array}$ & Texture & $\begin{array}{l}\mathrm{OM} \\
\%\end{array}$ & $\mathrm{pH}$ \\
\hline Oeiras & Portugal & $38^{\circ} 41^{\prime} \mathrm{N}$ & $9^{\circ} 18^{\prime} \mathrm{W}$ & 20 & Csa & 55.7 & 18.9 & 25.4 & $\begin{array}{l}\text { Sandy clay } \\
\text { loam }\end{array}$ & 1.4 & 8.0 \\
\hline $\begin{array}{l}\text { Arganda del } \\
\text { Rey }\end{array}$ & Spain & $40^{\circ} 19^{\prime} \mathrm{N}$ & $3^{\circ} 29^{\prime} \mathrm{W}$ & 550 & Csa & 35.9 & 44.3 & 19.8 & Loam & 1.3 & 7.8 \\
\hline Viladecans & Spain & $41^{\circ} 18^{\prime} \mathrm{N}$ & $2^{\circ} 0^{\prime} \mathrm{E}$ & 20 & Csa & 38.0 & 37.6 & 24.4 & Loam & 1.4 & 8.4 \\
\hline Legnaro & Italy & $45^{\circ} 20^{\prime} \mathrm{N}$ & $11^{\circ} 58^{\prime} \mathrm{E}$ & 15 & $\mathrm{Cfa}$ & 16.0 & 64.9 & 19.1 & Silt loam & 1.8 & 8.0 \\
\hline Zagreb & Croatia & $45^{\circ} 49^{\prime} \mathrm{N}$ & $16^{\circ} 01^{\prime} \mathrm{E}$ & 130 & $\mathrm{Cfb}$ & 66.7 & 30.0 & 3.3 & Sandy loam & 1.6 & 7.9 \\
\hline Belgrade & Serbia & $44^{\circ} 47^{\prime} \mathrm{N}$ & $20^{\circ} 27^{\prime} \mathrm{E}$ & 110 & $\mathrm{Cfb}$ & 8.0 & 66.6 & 25.4 & Silt loam & 1.3 & 8.0 \\
\hline
\end{tabular}

*Climate classification according to the updated Köppen-Geiger classification (Kottek et al., 2006).

98 2015), post hoc test using 1smean (Lenth, 2016), residual overdispersion was tested using DHARMa nonparametric overdispersion test, and homogeneity of residuals was tested using a Kolmogorov-Smirnov test on 1000 time resampled residuals, using DHARMa (Hartig, 2016) packages for R 3.3.2 (R core team,

10 2017). To evaluate the effect of climate on population emergence behaviour and germination-emergence conditions, climate classification of collection and experimental sites was tested in the mixed models as a fixed factor.

\section{Emergence modelling}

Emergence patterns of the different populations were compared within each experimental site and across the different experimental sites. Mean emergence patterns were identified at each site combining data from all populations. The version of AlertInf model adopted is based on the 'hydrothermal time concept' (Gummerson, 1986) and aims to simulate seedling emergence according to soil temperature and rainfall (Masin et al., 2010b). The first step involves the calculation of hydrothermal time accumulation (HT):

$$
\mathrm{HT}_{i}=\sum n * \max \left(T_{\mathrm{smi}}-T_{\mathrm{b}}, 0\right)+\mathrm{HT}_{i-1}
$$

where $T_{\text {smi }}\left({ }^{\circ} \mathrm{C}\right)$ is the average daily soil temperature of day $i$, and $T_{\mathrm{b}}\left({ }^{\circ} \mathrm{C}\right)$ is the base temperature for germination. To evaluate whether soil moisture content is limiting or not for germination, total rainfall in the preceding given number of days $(x)$ is compared with $P_{\text {limit }}(\mathrm{mm})$ that is the minimum total rainfall required to produce emergence. No HT accumulation $(n=0)$ is calculated if total rainfall in the past $x$ days is lower than $P_{\text {limit }}$, while HT accumulation occurs $(n=1)$ if it is higher than $P_{\text {limit }}$. The values of $T_{\mathrm{b}}, x$ and $P_{\text {limit }}$ for A. theophrasti, estimated in previous studies are reported in Table 3 and on the AlertInf webpage (http://www.arpa.veneto.it/upload_teolo/agrometeo/fix/ AlertInf $\% 20$ scheda $\% 20$ english.pdf).

When the accumulation of hydrothermal time $\left(\mathrm{HT}_{i}\right)$ has been calculated for a given day $i$, the corresponding cumulated total emergence percentage $\left(\mathrm{CE}_{i}\right)$ is determined by the following Gompertz equation:

$$
\mathrm{CE}_{i}=100 * \exp \left[-a * \exp \left(-b * \mathrm{HT}_{i}\right)\right]
$$

where $a$ represents an HT lag before seedling emergence starts and $b$ represents the rate of increase of seedling emergence once it is initiated. The values of $a$ and $b$ are species-specific and were estimated in previous studies (unpubl. obs.), they are reported in Table 3.

The starting point of accumulation of hydrothermal time is normally set at crop sowing or seedbed preparation date in the case of modelling weed emergence in crop fields. However, this approach was not feasible for this study. The starting point of accumulation was therefore established for each experimental site considering the first date of observation of emerged seedlings and counting backwards for a number of days (usually 3-5) necessary to accumulate the amount of HT corresponding to the lag before seedling emergence (approximately $20 \mathrm{HT}$ ), as estimated in previous unpublished studies. The AlertInf model was run independently for each experimental site using the local data of soil temperatures and rainfall. The Portuguese site of Oeiras was not included, due to the lack of appropriate soil

Table 3 Values of parameters adopted for the accumulation of hydrothermal time (HT, Eqn 1) and the estimation of cumulated percentage of total emergence (CE, Eqn 2)

\begin{tabular}{llllll}
\hline & $T_{\mathrm{b}}$ & $P_{\text {limit }}$ & $x$ & $a$ & $b$ \\
\hline HT (Eqn 1) & 3.9 & 4.5 & 12 & & \\
CE (Eqn 2) & & & & 5.486 & 0.0155 \\
\hline
\end{tabular}


temperature records. A single curve representing emergence dynamics of A. theophrasti was obtained for each site, and this was compared with the curves of observed mean emergence of the different populations, assessing AlertInf performance by calculating an efficiency index (EF) with the following equation (Loague \& Green, 1991):

$$
\mathrm{EF}=\frac{\sum_{i=1}^{n}\left(O_{i}-\bar{O}\right)^{2}-\sum_{i=1}^{n}\left(P_{i}-O_{i}\right)^{2}}{\sum_{i=1}^{n}\left(O_{i}-\bar{O}\right)^{2}}
$$

where $P_{i}$ is the predicted value, $O_{i}$ the observed value and $\bar{O}$ the mean of observed values. EF ranges from 1 (exact predictions) to a negative value, while an $\mathrm{EF}=0$ indicates a model of poor fit. The mean bias error (MBE) was also calculated. The MBE is an indication of the average deviation of the predicted from the observed values and is related to magnitude of values (Willmott, 1982).

$$
\mathrm{MBE}=\frac{1}{N} \sum_{i=1}^{N}\left(P_{i}-O_{i}\right)
$$

where $N$ is the number of observations, $P_{i}$ is the predicted value, and $O_{i}$ is the observed value. A negative MBE value indicates that the model is, on average, underestimating the observed values and vice versa (Wallach, 2006).

\section{Results}

\section{Seed weight}

Significant differences were detected among seed weights of the different populations (Appendix S1), with the highest values for populations from Catalonia and Greece $(10.4 \pm 0.04$ and $10.1 \pm 0.09 \mathrm{~g}$ for 1000 seed weight, respectively) and lowest for the population from Hungary $(8.4 \pm 0.04 \mathrm{~g}$ for 1000 seed weight).

\section{Weather conditions}

The experimental sites were characterised by diverse weather conditions (Fig. 1). The Belgrade and Zagreb sites experienced prolonged cold periods, with average daily air temperature below $10^{\circ} \mathrm{C}$ and minimum daily air temperature frequently close or below $0^{\circ} \mathrm{C}$ from December to mid-March. Winter was also cold at Arganda del Rey and Legnaro with average daily air temperature below $10^{\circ} \mathrm{C}$ from December to the end of February, while the Viladecans and Oeiras sites had warmer winter conditions. Considering the main seedling emergence period (February-July), the Oeiras and Viladecans sites had the highest mean temperatures
(21.5 and $17.1^{\circ} \mathrm{C}$, respectively) and the Zagreb and Belgrade sites the lowest (14.6 and $15.9^{\circ} \mathrm{C}$ respectively). Extreme differences were observed across the experimental sites regarding amounts of precipitation. From February to July, the three sites in the Iberian Peninsula (Oeiras, Arganda del Rey and Viladecans) received less than $200 \mathrm{~mm}$ of precipitation, while the other three (Legnaro, Belgrade and Zagreb) had more than $600 \mathrm{~mm}$.

\section{Emergence percentage}

The generalised mixed model identified significant effects $(P<0.001)$ of the population $\left(\chi^{2}=583.25\right.$, d.f. $=11 ; \quad P<0.001) \quad$ and experimental site $\left(\chi^{2}=883.66\right.$, d.f. $\left.=5 ; \quad P<0.001\right)$ factors and their interaction $\left(\chi^{2}=200.25\right.$, d.f. $\left.=55 ; P<0.001\right)$ on emergence percentage. Average emergence percentage varied notably, with significant differences among populations (Fig. 2). Populations from Minnesota, Catalonia and Iowa had the highest emergence percentage $(30.2 \pm 4.71,29.5 \pm 3.77$ and $28.4 \pm 4.07 \%$, respectively, mean of all sites) while the lowest percentage was observed for the Serbian population ( $4.5 \pm 0.53 \%$, mean of all sites). Similarly, significant differences were detected regarding the average emergence percentage of all populations pooled at the experimental sites (Fig. 3), with the highest percentage being at Belgrade and the lowest at Oeiras $(39.9 \pm 2.69$ and $6.8 \pm 1.02 \%$ respectively). However, wide variability was observed among the emergence percentages obtained by each population across the diverse experimental sites (Fig. 4). For example, the population from Minnesota reached $73.0 \pm 3.02 \%$ of emergence at Belgrade and only $9.1 \pm 2.00 \%$ at Arganda del Rey and the population from Iowa obtained $65.8 \pm 3.27 \%$ at Belgrade and $13.1 \pm 4.11 \%$ at Oeiras. Nevertheless, the ranking of the different populations in terms of emergence percentage remained quite similar across the diverse experimental sites, with the populations from Catalonia, Iowa and Minnesota reaching the highest emergence percentage in most sites.

Climate classification of experimental sites resulted as a not significant parameter $(P=0.164)$ in affecting emergence probability. Conversely climate classification of seed collection sites of the different populations significantly affected emergence percentage $\left(\chi^{2}=132.825\right.$, d.f. $=3 ; P<0.001)$ with a significant interaction with experimental site $\left(\chi^{2}=40.115\right.$, d.f. $\left.=15, P=0.006\right)$. When different populations were grouped according to the climate type of their seed collection sites, the general ranking of emergence percentage in all sites was $\mathrm{Cfb}$, Csa, Cfa and Df in ascending order, except for 

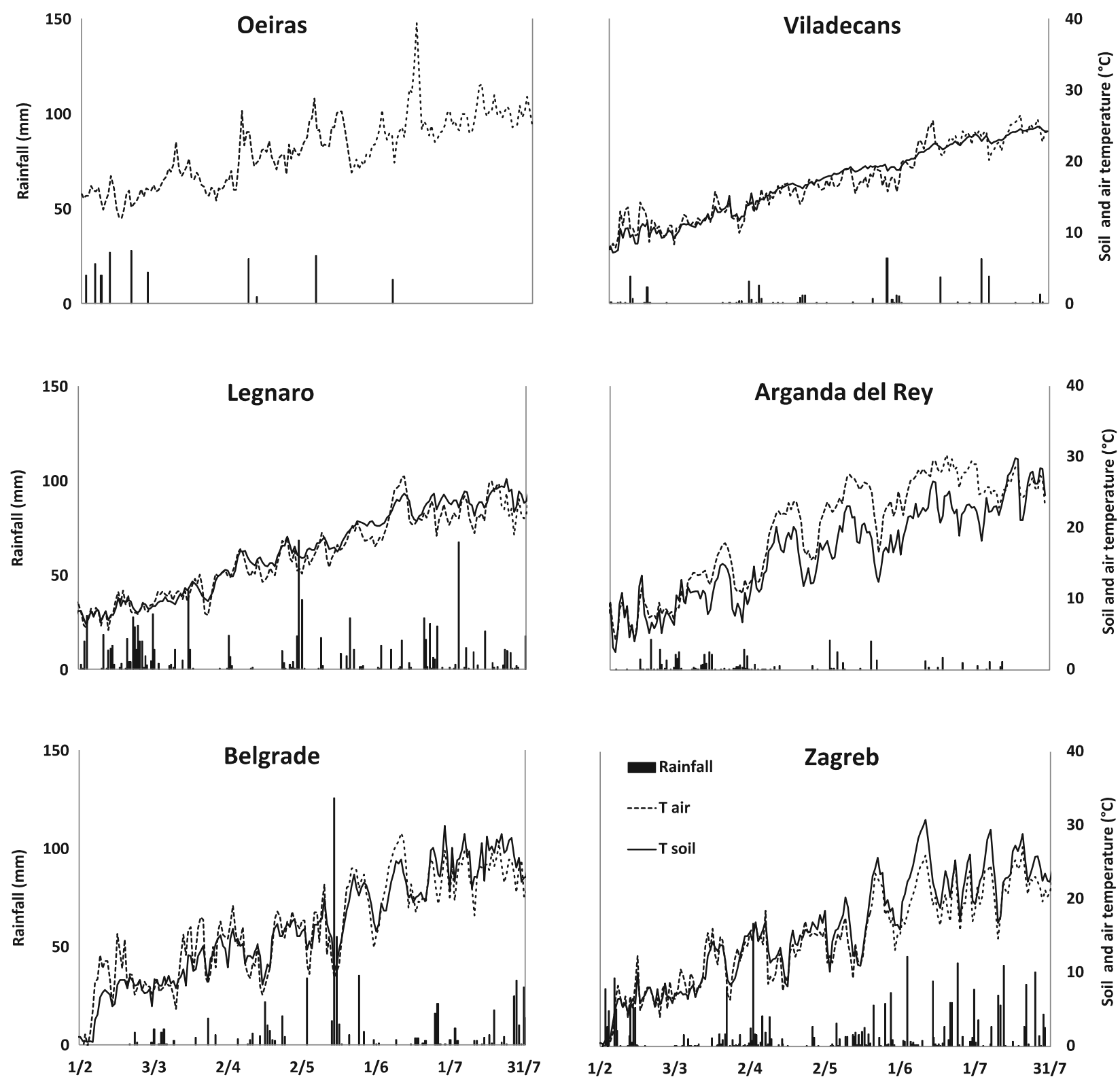

Fig. 1 Weather conditions at the experimental sites. Daily average soil and air temperature (continuous and dotted lines, respectively) and rainfall (bar) are reported.

Arganda del Rey where Cfa and Cfb showed a higher emergence percentage. The factor population explained emergence probability better than climate classification of the population seed collection site $(P<0.001)$.

\section{Emergence dynamics}

The first seedlings were observed around mid-February at Oeiras, Arganda del Rey, Viladecans and Legnaro, whereas only on 13 and 21 March at Belgrade and Zagreb (Fig. 5). Considering all populations at each experimental site, the main emergence period lasted approximately from 6 (Arganda del Rey and Belgrade) to 10 weeks (Legnaro). No seedlings emerged at Arganda del Rey after the end of April, while almost $15 \%$ of total emerged seedlings at Legnaro were observed after the end of May. Although the single populations of $A$. theophrasti presented different emergence patterns across the six experimental sites, some tendencies were consistent. The populations from Iowa and Minnesota showed earlier emergence dynamics in comparison with the other populations at almost all sites, while the population from Portugal had later emergence dynamics (Fig. 5). The amplitude of these differences varied across the experimental sites, with a minimum level at Arganda del Rey where the emergence dynamics of the various populations were almost identical. The emergence 


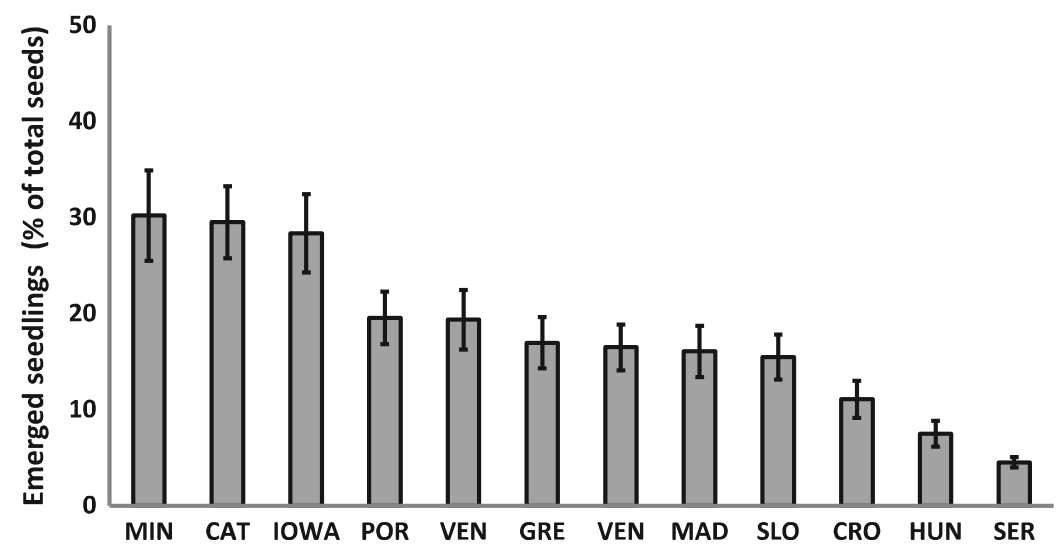

Fig. 2 Percentage of emerged seedlings on the total number of seeds for the different populations of Abutilon theophrasti. Values are means of each population across the six experimental sites $(n=24$; d.f. $=288)$. Vertical bars represent SE.

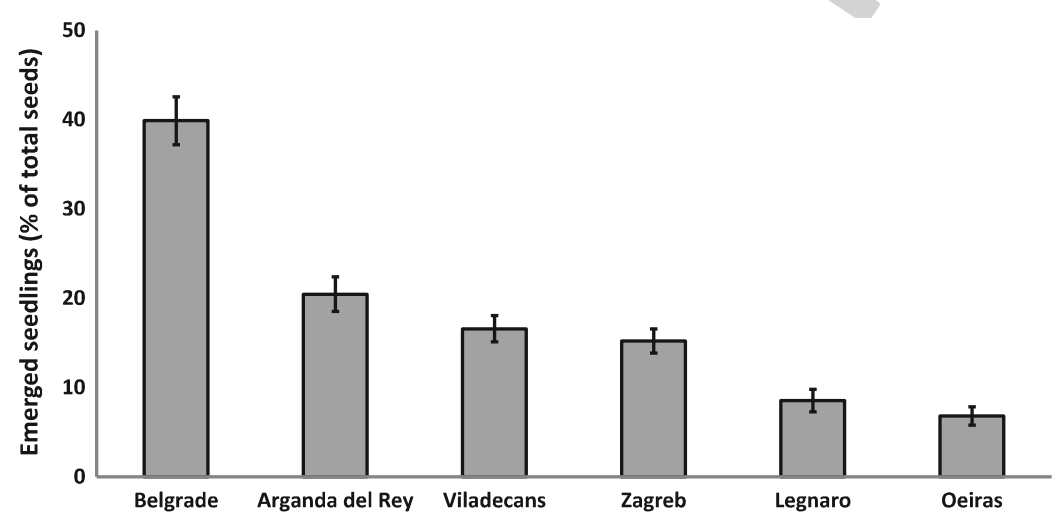

Fig. 3 Percentage of emerged seedlings on the total number of seeds at the experimental sites. Values are means of all populations at each experimental site $(n=48$; d.f. $=288)$. Vertical bars represent $\mathrm{SE}$.

dynamics of all populations at all experimental sites are reported in Appendix S2.

When the emergence dynamics observed at the different sites were compared according to accumulated hydrothermal time (HT) instead of calendar days, differences among sites decreased. Most seedling emergence occurred within 500 HT at all sites, even if it was prolonged after $1000 \mathrm{HT}$ in the case of late-emerging populations at Legnaro and Zagreb (Fig. 6).

Accuracy of the AlertInf simulation varied across the different sites and populations. Good simulation accuracy was obtained in general at Arganda del Rey and Belgrade, with EF values above 0.85 for most populations. Contrasting results were instead observed between the simulation accuracy for the different populations at Legnaro, where AlertInf simulated the emergence curves of MIN and IOWA populations with high accuracy $(\mathrm{EF}=0.97)$, while it notably overestimated the emergence curves of other populations such as CAT, GRE and SLO (EF $<0.2, \mathrm{MBE}>25)$. Intermediate situations were observed for AlertInf accuracy at Zagreb and Viladecans with a general slight overestimation, identified by the positive MBE values of the predicted emergence curves in comparison with the observed data for the different populations. Considering the results for the different populations across all the sites, high and stable simulation accuracy was obtained for MIN and IOWA populations (EF values always above 0.87), while relevant variability was observed for CAT (EF ranging from 0.99 to 0.19 ), GRE (EF ranging from 0.95 to -0.42 ) and SLO (EF ranging from 0.99 to -0.03 ). The values of EF and MBE for all populations at all experimental sites are reported in Appendix S3.

\section{Discussion}

\section{Variability across experimental sites}

Weather conditions at the end of winter determined the start of emergence at the different experimental sites. The lower temperatures at Belgrade and Zagreb during January and February 2014 delayed seedling emergence by almost 1 month in comparison with the other sites (from mid-February to mid-March). Even a 


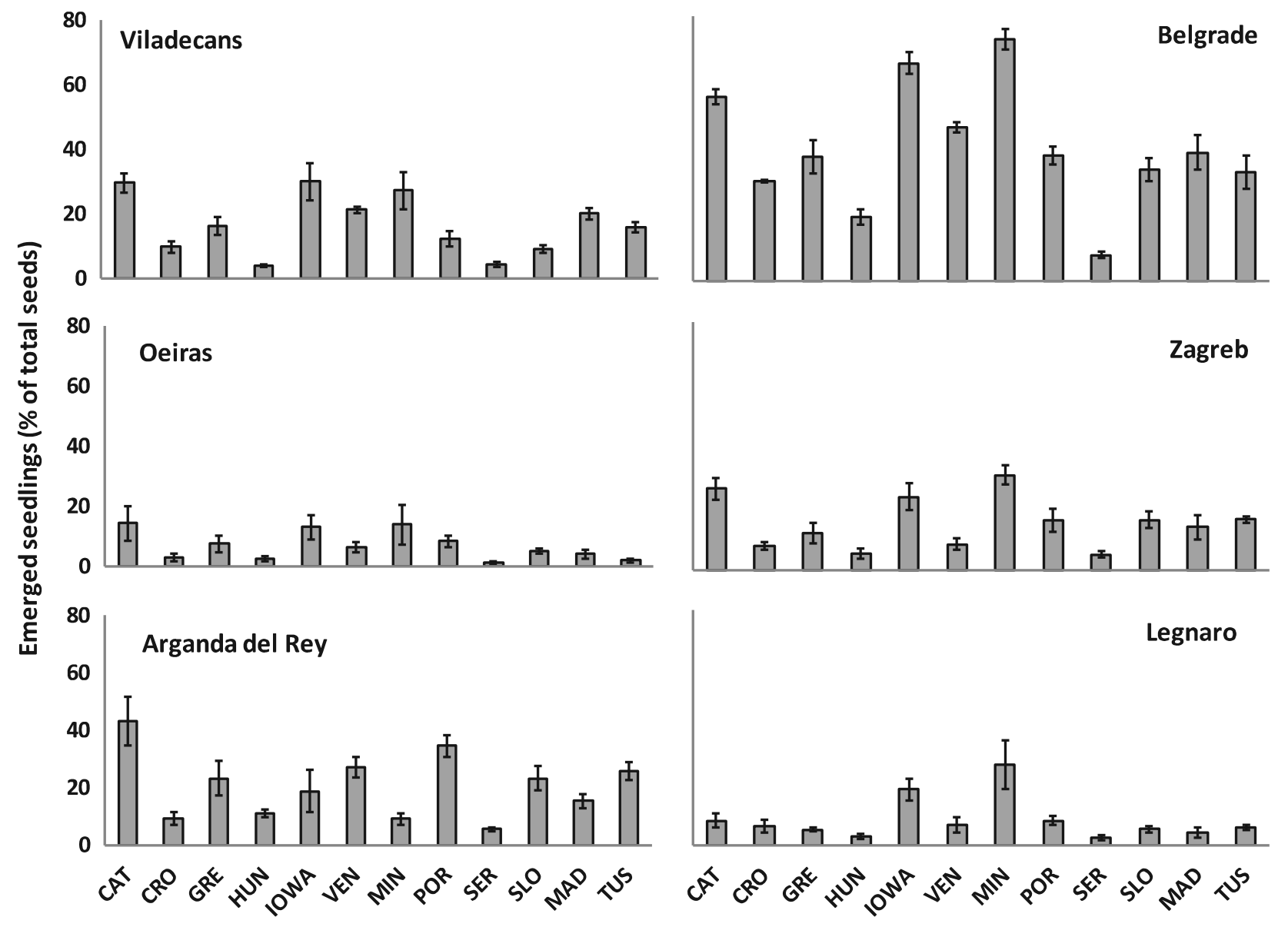

Fig. 4 Percentage of emerged seedlings on the total number of seeds for the different Abutilon theophrasti populations at the six experimental sites. Values are means of each population at each experimental site $(n=4$; d.f. $=288)$. Vertical bars represent SE.

few degrees of difference in average temperatures can substantially modify the emergence dynamics, considering that in previous laboratory experiments the start and $50 \%$ of germination were observed after 5 and 7 days of incubation at $8^{\circ} \mathrm{C}$, respectively, while only after 3 and 4 days at $10^{\circ} \mathrm{C}$ (Loddo, unpubl. obs.). Moreover, the minimum daily air temperature in that period remained close or below $0^{\circ} \mathrm{C}$ for weeks at the two sites, causing a relevant limitation for seed germination.

In contrast, winter temperatures were reported to not considerably affect physical dormancy of A. theophrasti seeds that usually declines rapidly during the first autumn after seed dispersal and then remains stable during the following winter and spring (Cardina \& Sparrow, 1997). Environmental conditions during winter months were instead reported to influence seed decay; in particular, Schutte et al. (2008) suggested that prolonged exposure to wet soil conditions could increase inner osmotic pressure of A. theophrasti seeds and consequently soften and damage the seed coat, facilitating microbial attack. However, previous studies reported an extremely variable range of overwinter seed decay, from $2 \%$ of initial seedbank (Gómez et al., 2014) to $16 \%$ or even above 40\% (Buhler \& Hartzler, 2001; Davis et al., 2006;). Different levels of seed decay could therefore be supposed for the various populations at the six experimental sites, according to the interaction of local environmental conditions and seed coat characteristics of each population. However, measuring this process or estimating its impact on seedling emergence was beyond the aim of this study. Precipitation patterns notably influenced the emergence dynamics at the different experimental sites; in particular, the abundance or scarcity of rainfall during May and June determined the prolongation of emergence flushes till early summer. Considering the four sites (Oeiras, Arganda del Rey, Viladecans and Legnaro) where seedling emergence started simultaneously in mid-February, Legnaro had the highest amount of precipitation (approximately $160 \mathrm{~mm}$ ) from May to June and $20 \%$ of total emergence occurred in this period. The Oeiras and Viladecans sites presented a medium-low amount of precipitation (40 and $60 \mathrm{~mm}$, respectively) in the same period and only $10 \%$ of total seedlings emerged from 

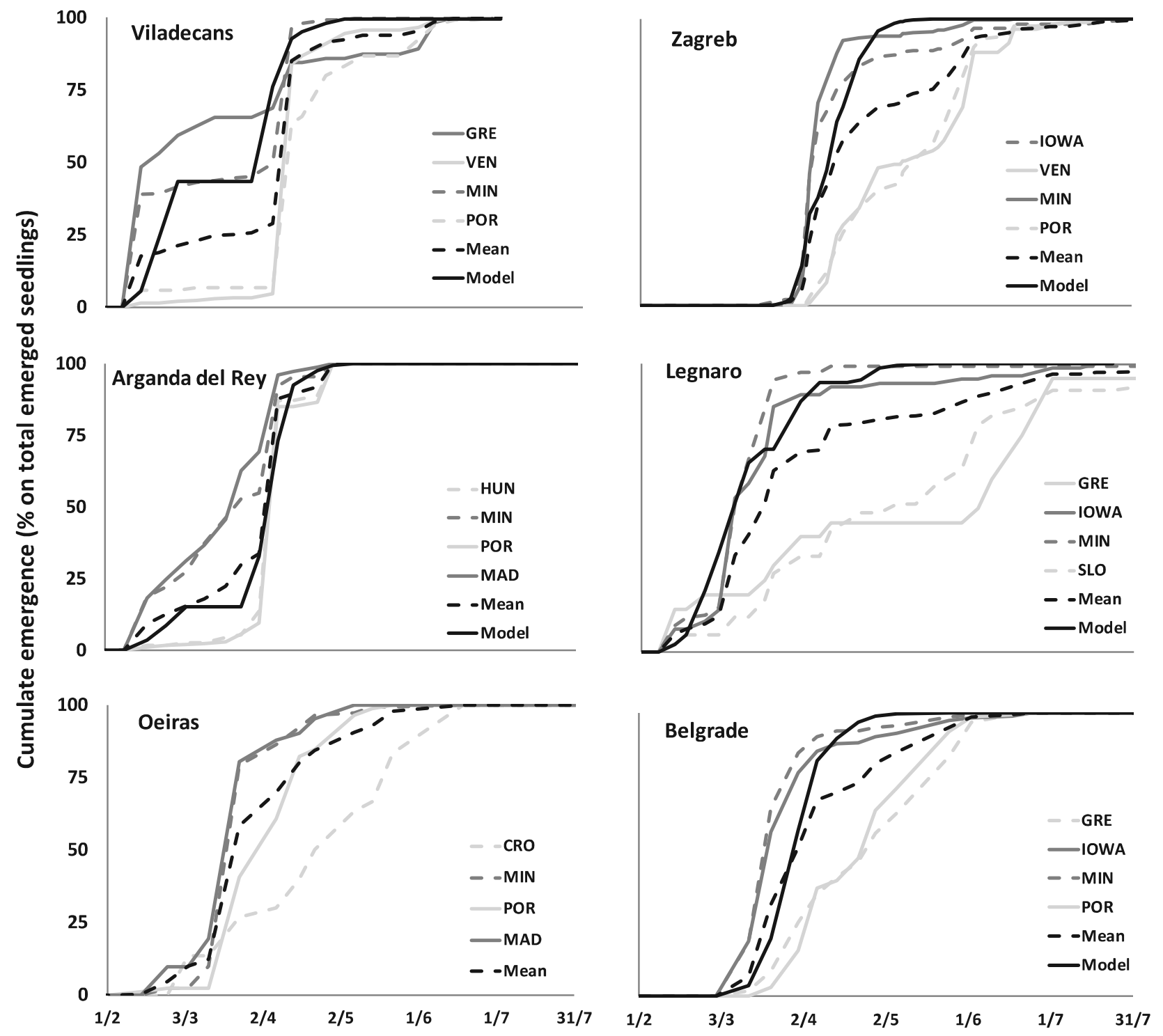

Fig. 5 Cumulative emergence of the different Abutilon theophrasti populations (expressed as \% of total emerged seedlings for each population) during the main seedling emergence period (1 February-31 July 2014). The two earliest (dark grey lines) and latest emerging (light grey lines) populations for each experimental site are reported. Values are means of three replicates. Mean cumulative emergence dynamics (black dotted lines) estimated considering all the populations and the emergence curves predicted by AlertInf model (black continuous lines) are reported.

May to June. Lastly, precipitation was scarce at Arganda del Rey ( $25 \mathrm{~mm}$ in the 2 months), and consequently, no emergence was reported from May onwards. Variability in seedling emergence observed across the six experimental sites could therefore be considered a result of the interaction between local environmental conditions and seed characteristics (dormancy, germinability, seed coat thickness) of the different populations. This interaction could affect the various processes leading to seedling emergence, that is seed decay and persistence, dormancy release, germination and emergence. Comprehensive knowledge on the specific effect of the different environmental factors on seedbank dynamics has not yet been attained for
A. theophrasti. AlertInf and some other existing models (Archer et al., 2006) are able to simulate the temporal dynamics of seedling emergence for A. theophrasti according to weather trends, while estimating emergence magnitude according to the environmental conditions is still extremely difficult.

\section{Variability among the populations}

Regardless of the variability observed across the experimental sites, different behaviours in the emergence patterns could be detected among populations. Since these differences remained consistent across the six sites, their origin could be related to interpopulation 


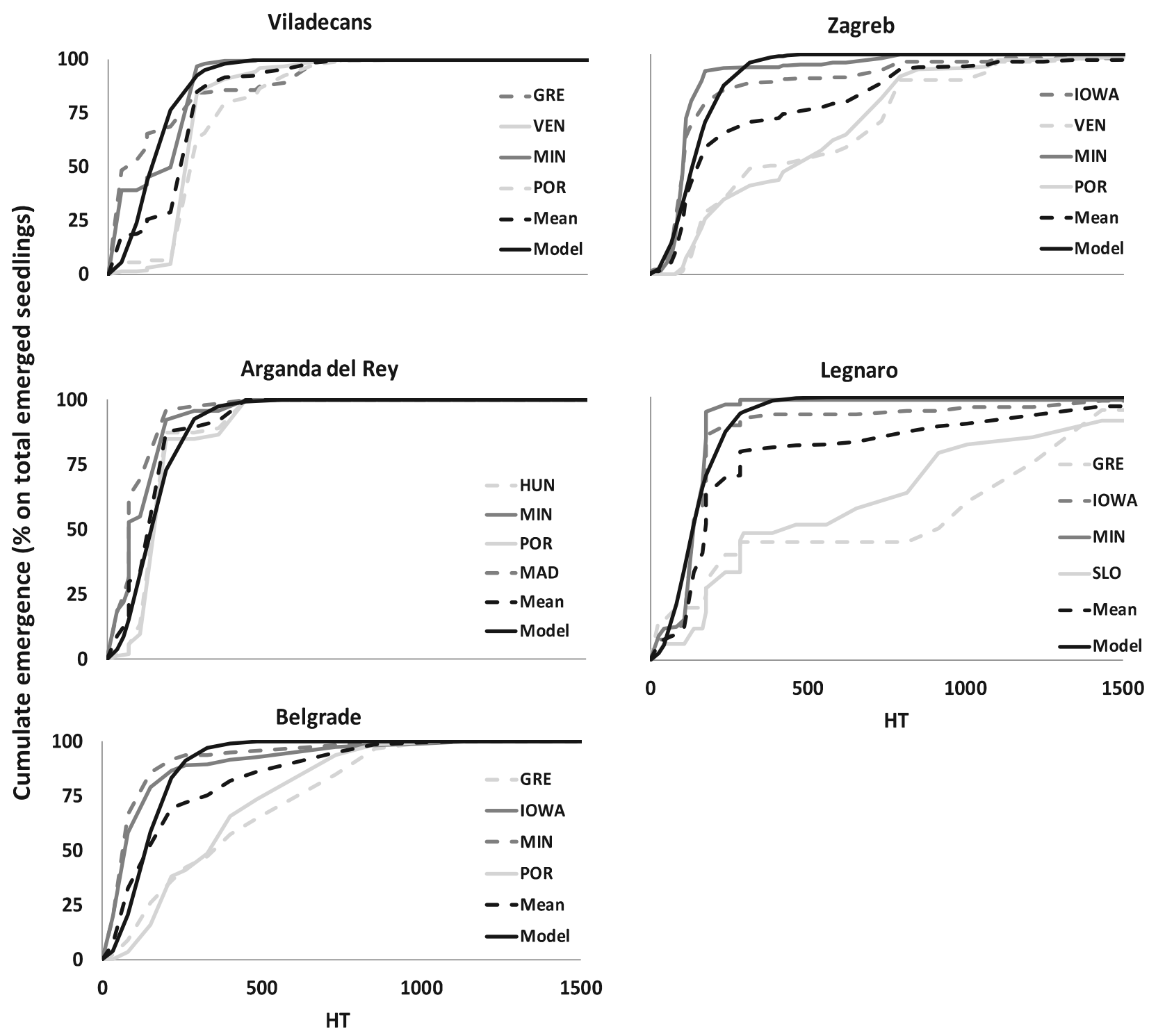

Fig. 6 Cumulative emergence of the different Abutilon theophrasti populations (as \% of total emerged seedlings for each population) during the main seedling emergence period (1 February-31 July 2014) expressed on the basis of hydrothermal time accumulation (HT) estimated at each experimental site. The two earliest (dark grey lines) and latest emerging (light grey lines) populations for each experimental site are reported. Values are means of three replicates. Mean cumulative emergence dynamics (black dotted lines) estimated considering all the populations and the emergence curves predicted by AlertInf model (black continuous lines) are reported.

variability regarding seed dormancy level. Populations from Catalonia, Iowa and Minnesota, which reached higher emergence percentage and presented earlier and more concentrated emergence flushes, probably had a lower dormancy level. An intermediate condition could be supposed for populations coming from Greece, Veneto, Tuscany, Madrid, Portugal and Slovenia that obtained average emergence percentages with later and more prolonged emerge flushes. Lastly, populations from Croatia, Serbia and Hungary probably had a higher level of seed dormancy given their low average emergence percentage. Variability in seed dormancy level and base temperatures for germination among local populations has already been reported for various weed species (Loddo et al., 2013, 2014; Tozzi et al., 2014). However, similar values of base temperature for germination were detected in several studies for A. theophrasti populations coming from different countries, after the removal of seed physical dormancy by chemical or mechanical scarification (Masin et al., 2010a,b; Loddo et al., 2013, 2018). As a consequence, the variability in seed physical dormancy, that is in seed coat characteristics, could be supposed to be responsible for the differences in emergence patterns for the various $A$. theophrasti populations. Differences in seed coat among populations could be related to 
genetic interpopulation variability as a result of adaptation processes to local environmental conditions. Populations from Iowa and Minnesota could have a lower level of seed physical dormancy as an adaptation to the local climatic conditions at Morris and Monona, which are significantly colder than the other collection sites, since being able to germinate as soon as soil conditions are favourable is an important adaptation to complete the annual life cycle in areas with a short growing season. However, this could hardly be proposed as the only explanation for germination behaviour of the population from Catalonia, since the Lleida collection site climate is classified as warm temperate, similarly to many other collection sites. Maternal effect, that is environmental conditions during mother plants' growth and seed ripening, is known to strongly affect seed coat characteristics. For example, Cardina and Sparrow (1997) observed that A. theophrasti seeds produced by mother plants grown in warmer, drier conditions had a thicker seed coat and higher level of physical dormancy. Nevertheless, this cannot be supposed as the main driving factor for the dormancy variability observed in this study because seeds were mainly collected in irrigated crop fields and mother plants therefore probably did not experience relevant water stress. Moreover, the populations with the highest dormancy levels (i.e. those from Croatia, Serbia and Hungary) were collected in sites with the lowest summer temperatures. The presence of crop competition during mother plant growth was also reported to influence seed coat weight (Nurse \& DiTommaso, 2005), but no information regarding this was available for the different collection sites. The interaction of genetic factors and maternal effect could determine year-by-year differences in seed coat characteristics, and consequently in seed dormancy level, even for the same population and the same location, as already observed by Schutte et al. (2008). It was not possible to quantify with the present study the specific contribution of genetic factors and environmental factors (i.e. the maternal effect) in determining the different dormancy levels observed for the A. theophrasti populations and further experiments are required to adequately address this issue. For example, growing the different populations at the same site, according to the so-called 'common garden' experimental methodology (Loddo et al., 2014), would make the maternal environment uniform, consequently the effect of genetic factors on dormancy level of seeds produced by the different populations could be adequately evaluated. Improving our knowledge of these processes is important within a control perspective. Populations with early and concentrated flushes of seedling emergence can generate strong competition with crops, but at the same time several control tools can be effective, such as false or stale seedbed, pre-emergence or postemergence herbicides. In contrast, populations with late and prolonged emergence flushes would reasonably be less competitive against crops. However, some of the late-emerging seedlings can escape control tools that are applied before their emergence and go on to produce significant seed rain. In similar situations, postponing control operations and switching from preemergence to post-emergence herbicide application could be necessary. Moreover, populations with low dormancy level can present large and problematic seedling emergence in the first 1-2 years after dispersal but their seedbank persistence is consequently limited. If control strategies succeed in killing emerged seedlings and avoiding further dissemination, seedbank depletion will occur in a few years. Instead, populations with dormant seeds do not have large seedling emergence in the first years after dissemination, so competition with crops will probably be lower but seedbank persistence longer and its depletion difficult. Acquiring better knowledge of the different aspects and effects of interpopulation variability could therefore allow more specific and efficient control strategies to be designed, facilitating the replacement of solely herbicide-based management with true IWM strategies involving alternative and complementary tools and tactics. This is a key component of the present evolution in weed management for addressing the societal challenge both to increase food production and to reduce the environmental impact of agriculture (Liebman et al., 2016).

Finally, rather encouraging indications emerged from the test of the AlertInf model. Good predictive accuracy of the emergence dynamics of the different populations was obtained at Arganda del Rey and Belgrade, where higher emergence percentage and more concentrated emergence flushes were observed for all populations. However, the AlertInf model was not able to accurately simulate emergence dynamics of lateemerging populations, especially in the case of low emergence percentage, and this caused the contrasting results obtained for the different populations at Legnaro, with very good accuracy for the early-emerging IOWA and MIN and marked overestimation instead of the two late-emerging GRE and SLO. This situation could probably be due to the fact that AlertInf model was developed, calibrated and validated under arable field conditions, where soil tillage for seedbed preparation tends to stimulate $A$. theophrasti seed germination producing concentrated seedling emergence flushes. However, achieving good predictive accuracy is generally difficult in the case of populations with low emergence percentage, such as GRE and SLO at Legnaro, because their emergence curves are usually irregular 
due to the limited number of observations of emerged seedlings. The possibility of adopting the AlertInf model across a quite wide range of environmental conditions and $A$. theophrasti populations can be therefore supposed. Nevertheless, further experiments are necessary to calibrate the parameters of its equations according to the intra-specific variability of seed dormancy.

\section{Acknowledgements}

This study was supported by Padova University Research Project CPDA144499: 'Mitigazione della contaminazione da erbicidi delle acque superficiali in agricoltura conservativa con la combinazione di misure in-field e edge-of-field'. The authors are grateful to Alison Garside for revising the English text.

\section{References}

Andersson L \& Milberg P (1998) Variation in seed dormancy among mother plants, populations and years of seed collection. Seed Science Research 8, 29-38.

Archer DW, Forcella F, Korth A, Kuhn A, Eklund J \& SPOKAS K (2006) WeedCast version 4.0. Available at: http://www.ars.usda.gov

Bates D, Maechler M, Bolker B \& Walker S (2015) Fitting linear mixed-effects models using lme4. Journal of Statistical Software, 67, 1-48.

Berti A, SAttin M, BAALdoni G et al. (2008) Relationships between crop yield and weed time of emergence/removal: modelling and parameter stability across environments. Weed Research 48, 378-388.

Buhler DD \& HARTZLER RG (2001) Emergence and persistence of seed of velvetleaf, common waterhemp, woolly cupgrass, and giant foxtail. Weed Science 49, 230-235.

CARdina J \& Sparrow DH (1997) Temporal changes in velvetleaf (Abutilon theophrasti) seed dormancy. Weed Science 45, 61-66.

Davis AS, Anderson KI, Hallett SG \& Renner KA (2006) Weed seed mortality in soils with contrasting agricultural management histories. Weed Science 54, 291-297.

Dorado J, Sousa E, Cahla IM, Gonzalez-Andujar JM \& FernándeZ-Quintanilla C (2009a) Predicting weed emergence in maize crops under two contrasting climatic conditions. Weed Research 49, 251-260.

Dorado J, Fernández-Quintanilla C \& Grundy AC (2009b) Germination patterns in naturally chilled and nonchilled seeds of fierce thornapple (Datura ferox) and velvetleaf (Abutilon theophrasti). Weed Science 57, 155-162.

Eslami SV (2011) Comparative germination and emergence ecology of two populations of common lambsquarters (Chenopodium album) from Iran and Denmark. Weed Science 59, 90-97.

Gardarin A, Dürr C, Mannino Mr, Busset H \& Colbach N (2010) Seed mortality in the soil is related to seed coat
Gesch RW, Royo-Esnal A, Edo-Tena E, Recasens J, Isbell TA \& ForCella F (2016) Growth environment but not seed position on the parent plant affect seed germination of two Thlaspi arvense L. populations. Industrial Crops and Products 84, 241-247.

Gómez R, Liebman M \& Munkvold G (2014) Weed seed decay in conventional and diversified cropping systems. Weed Research 54, 13-25.

Gummerson RJ (1986) The effect of constant temperatures and osmotic potential on the germination of sugar beet. Journal of Experimental Botany 41, 1431-1439.

HARTIG F (2016) DHARMa: residual diagnostics for hierarchical (multi-level/mixed) regression models. $\mathrm{R}$ package version 0.1.0.

Karlsson LM, Tamado T \& Milberg P (2008) Inter-species comparison of seed dormancy and germination of six annual Asteraceae weeds in an ecological context. Seed Science Research 18, 35-45.

Kottek M, Grieser J, Beck C, Rudolf B \& Rubel F (2006) World map of the Köppen-Geiger climate classification updated. Meteorologische Zeitschrift 15, 259-263.

LENTH RV (2016) Least-squares means: the R package lsmeans. Journal of Statistical Software 69, 1-33.

Liebman M, Miller ZJ, Williams CL et al. (2014) Fates of Setaria faberi and Abutilon theophrasti seeds in three crop rotation systems. Weed Research 54, 293-306.

Liebman M, Baraibar B, Buckley Y et al. (2016) Ecologically sustainable weed management: how do we get from proof-of- concept to adoption? Ecological Applications 26, p1352-p1369.

Loague K \& Green RE (1991) Statistical and graphical methods for evaluating solute transport models: overview and application. Journal of Contaminant Hydrology 7, 5173.

Loddo D, Sousa E, Masin R et al. (2013) Estimation and comparison of base temperatures for germination of European populations of velvetleaf (Abutilon theophrasti) and jimsonweed (Datura stramonium). Weed Science 61, 443-451.

Loddo D, Sousa E, Masin R et al. (2014) Germination response of local Southern European populations of Datura stramonium at a range of constant temperatures. Weed Research 54, 356-365.

Loddo D, Ghaderi-Far F, Rastegar Z \& Masin R (2018) Base temperatures for germination of selected Iranian weed species. Plant Protection Science 54, 60-66.

Masin R, Loddo D, Benvenuti S, Zuin MC, Macchia M \& ZANin G (2010a) Temperature and water potential as parameters for modeling weed emergence in CentralNorthern Italy. Weed Science 58, 216-222.

Masin R, Cacciatori G, Zuin MC \& Zanin G (2010b) AlertInf: an emergence predictive model for weed control in maize in Veneto. Italian Journal of Agrometeorology 15, 5-9.

Masin R, Loddo D, Benvenuti S, Otto S \& Zanin G (2012) Modeling weed emergence in Italian maize fields. Weed Science 60, 254-259.

Masin R, Loddo D, Gasparini V, Otto S \& Zanin G (2014) Evaluation of weed emergence model AlertInf for maize in soybean. Weed Science 62, 360-369. 
Nurse RE \& DiTommaso A (2005) Corn competition alters the germinability of velvetleaf (Abutilon theophrasti) seeds. Weed Science 53, 479-488.

Recasens J, Calvet V, Cirujeda A \& Conesa JA (2005) Phenological and demographic behaviour of an exotic invasive weed in agroecosystems. Biological Invasions 7, $17-27$.

Schutte BJ, Davis AS, Renner KA \& Cardina J (2008) Maternal and burial environment effects on seed mortality of velvetleaf (Abutilon theophrasti) and giant foxtail (Setaria faberi). Weed Science 56, 834-840.

Tozzi E, Beckie H, Weiss R et al. (2014) Seed germination response to temperature for a range of international populations of Conyza canadensis. Weed Research 54, 178-185.

Vrbnicanin S, OnC-Jovanovic E, Bozic D et al. (2017) Velvetleaf (Abutilon theophrasti Medik.) productivity in competitive conditions. Archives of Biological Sciences 69, $157-166$

WaLlach D (2006) Evaluating crop models. In: Working with Dynamic Crop Models: Evaluation, Analysis, Parameterization, and Applications (eds D Wallach, D
Makowski \& JW Jones), 11-54. Elsevier, Amsterdam, the Netherlands.

WiLlmott CJ (1982) Some comments on the evaluation of model performance. Bulletin of the American

Meteorological Society 63, 1309-1313.

\section{Supporting Information}

Additional supporting information may be found online in the Supporting Information section at the end of the article.

Appendix S1. Seed weight of the different Abutilon theophrasti populations

Appendix S2. Emergence dynamics of all Abutilon theophrasti populations

Appendix S3. Assessment of AlertInf performance at the different sites by a comparison of the predicted emergence curves with the observed mean emergence curves of the different populations 